AUREG

PNL-3020

\title{
Training and Qualifying Personnel for Performing Measurements for the Control and Accounting of Special Nuclear Material
}

Prepared by R. J. Brouns, F. P. Roberts

Pacific Northwest Laboratory

Operated by

Battelle Memorial Institute

Prepared for

U.S. Nuclear Regulatory

Commission 


\section{NOTICE}

This report was prepared as an account of work sponsored by an agency of the United States Government. Neither the United States Government nor any agency thereof, or any of their employees, makes any warranty, expressed or implied, or assumes any legal liability or responsibitity for any third party's use, or the results of such use, of any information, apparatus product or process disclosed in this report, or represents that its use by such third party would not infringe privately owned rights.

Availabie from

GPO Sales Program

Division of Technical Information ana Document Control

U. S. Nuclear Regulatory Comissior: dasinington, 0.0 .20555

and 


\section{Training and Qualifying Personnel for Performing Measurements for the Control and Accounting of Special Nuclear Material}

Manuscript Completed: June 1980

Date Published: November 1980

Prepared by

R. J. Brouns, F. P. Roberts

Pacific Northwest Laboratory

Richland, WA 99352

Prepared for

Division of Siting, Health and Safeguards Standards

Office of Standards Development

U.S. Nuclear Regulatory Commission

Washington, D.C. 20555

NRC FIN No. B2014 
$+1$

- i 
$\underline{\text { ABSTRACT }}$

This report presents general procedures for training and qualifying personnel who perform sampling and measurements used for special nuclear material accounting. Considerations for establishing training and qualifying procedures are discussed. 


\begin{abstract}
,
\end{abstract}




\section{SUMMARY}

The quality of measurements made for special nuclear material accounting can be affected by the training and experience of the persons perfoming the measurement and sampling activities. A training and qualifying program can help ensure that these persons are adequately qualified to perfom the measurements. The program consists of defining the job requirements, selecting appropriate candidates, and training and qualifying the candidates. The qualification involves testing and observation of candidates' performance of the job functions under realistic circumstances and evaluating their competence to perform the functions. Records of the training and qualification provide certification that the individual is authorized to perform the measurement or sampling job. 


\section{$\cdot$}




\section{TABLE OF CONTENTS}

Page

\begin{tabular}{|c|c|c|c|c|c|c|c|c|c|c|}
\hline \multicolumn{2}{|c|}{ ABSTRACT } & . & . & - & • & . & • & & & $i i i$ \\
\hline \multicolumn{2}{|c|}{ SUMMARY } & . & . & - & . & $\cdot$ & - & & & \\
\hline 1.0 & \multicolumn{3}{|c|}{ INTRODUCTION } & - & . & . & . & & & ? \\
\hline \multirow[t]{6}{*}{2.0} & \multicolumn{5}{|c|}{ RECOMMENDED QUALIFYING } & \multicolumn{2}{|c|}{ PROGRAM } & & & \\
\hline & 2.7 & Selecti & & of $\mathrm{C}_{\mathrm{a}}$ & andi & idat & & & & \\
\hline & 2.2 & Trainin & & . & . & . & . & & & \\
\hline & 2.3 & Qualifi & icat & ion & . & . & . & & & \\
\hline & 2.4 & Requali & ifici & ation & & . & . & & & 6 \\
\hline & 2.5 & Certifi & cat & ion & . & • & . & & & \\
\hline REFE & ENCE & & 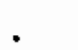 & . & . & . & , & & & \\
\hline
\end{tabular}




\section{$-$}

$-\cdots$ 


\subsection{INTRODUCTION}

Licensees who are required to implement and maintain measurement control programs for special nuclear materials accounting as specified in 10 CFR 70.57 are also required to establish procedures and performance criteria for the training and qualification of personnel who perform sampling and measurements for SNM accounting. (1) The purposes of this requirement are to ensure that:

- Persons performing sampling and measurement functions have been adequately trained in the operations to which they are assigned.

- A qualification program is maintained for employees to demonstrate their capabitities to perform specific sampling and measurement operations with an acceptable level of accuracy and precision before they are allowed to perform material control and accounting measurements.

- A program of periodic requalification of employees is maintained to demonstrate a continued capability to perform sampling and measurement operations with an acceptable level of accuracy and precision, and reflects any changes that are made in job assignments.

- Variations in measurement quality performance among operators are reduced.

- The training and qualification programs are carried out in an effective manner.

This report was prepared by PNL for the Office of Standards Development of the Nuclear Regulatory Commission on a program to develop guidelines for improving measurement control for special nuclear materials accounting.

The report does not necessarily represent NRC policy on the acceptable level of training and aualification for material control and accountino personnel. 


\subsection{RECOMMENDED QUALIFYING PROGRAM}

The training and qualifying of measurement personnel require:

- Selection of candidates for the measurement jobs.

- Training to meet the job requirements, and training in any new procedures.

- Qualification to demonstrate that the individual is capable of performing the job functions.

- Periodic requalification to provide continued assurance that the individual retains competence to perform the job functions.

- Certification to provide documentation of the qualification.

Each of these requirements is discussed in the following sections.

\subsection{SELECTION OF CANDIDATES}

The skill and knowledge prerequisites for a measurement job can be specified in terms of education, training, and experience needed for satisfactory performance of the job functions. A job description that describes the duties and functions and the required skill and knowledge can best be prepared by management. Minimum requirements should be specified and applied when selecting candidates for training and qualification for SNM measurements.

\subsection{TRAINING}

Candidates selected to be trained should be given an orientation to the job and such training as necessary to ensure that the individual has acquired the knowledge and has been instructed in the procedures and techniques necessary for satisfactory performance of the job. The training program may consist primarily of on-job instruction. The instructor should be a skilled technician or scientist qualified and experienced in the measurement job. Instruction in theory and principles pertaining to a measurement procedure and to the equipment or instruments used, and a survey of the relevant processing technology should be included. Special short courses or training institutes (such as those conducted by equipment 
manufacturers) may be used to obtain specialized training in such areas as calibrations of weights, volumetric vessels and instruments, and use of complex instruments such as mass spectrometers and nondestructive assay systems. Training may also involve formal courses, seminars, or individual studies including such subjects as basic mathematics and statistics, chemistry, physics, quality control, automatic data processing, and electronics.

Upon implementation of a measurement control program, it is necessary to qualify the present employees who are performing material control and accounting measurement activities. Some of the technical and scientific employees may require training in order to be qualified, while others may not. In either case, the level of proficiency of employees and any needed training should be determined by tests such as a demonstration of competence to perform assigned activities within predetermined levels of accuracy and precision. Training and qualification of employees should also be performed whenever a new method of sampling or measurement is introduced.

\subsection{QUALIFICATION}

The qualification of a person for a sampling or a measurement position is based on an evaluation of job performance capability. Job performance capabilities can be evaluated by use of the following:

- Oral and/or written testing.

- Observation of performance and assessment of capability by a supervisor or by others designated by him.

- Demonstration by a candidate of performance capability for prescribed job tasks.

- Determination of the accuracy and precision obtained by a candidate in repeated measurements of reference materials.

The combination of both direct observation and quantitative measures of performance of presestablished job tasks provide a principal basis for evaluation. The accuracy and precision obtained by a candidate are effective measures of sampling and measurement performance. For example, 
a candidate in an analytical laboratory may be required to analyze a predetermined number of test standards representative of the work to be performed for each analytical method for which he is being qualified. The accuracy and precision obtained by the employee are evaluated against predetermined qualification criteria. (2) In certain cases, e.g., sampling, a subjective judgment of a candidate's demonstrated skill and knowledge in performing operating procedures may be acceptable.

Evaluation may also include other tests that are considered appropriate by management for specific jobs. Examples are tests on principles and theory, process technology, and pertinent technical information. The evaluation criteria for each job should be pre-established and reviewed by the measurement control program management, and documented.

Qualification tests should be carried out under the direct observation of a qualified examiner who should verify that the measurements were carried out in accordance with written procedures. The examiner should be qualified in the procedure for which the candidate is being tested, and should have sufficient training and experience to properly administer the tests and to evaluate the results. The examiner should be thoroughly familiar with the scope and the limitations of the procedures for which the candidate is to be qualified.

Specific qualification criteria should be established for each measurement method and the stringency of the qualification criteria should be proportional to the potential impact of the method on the accuracy and precision of material control and accounting results. For instance, the potential relative contribution of each method to a plant's ID, variance of ID, and shipper/receiver differences should be considered in establishing qualification criteria.

Since accuracy and precision of measurement results are the ultimate measures of the candidate's perfomance, consideration should be given to using tests like those developed by Huff and Tingey. (2) As an example, for candidates who are to perform chemical or nondestructive analyses or weighings, the test should include performing duplicate measurements on disguised samples (having compositions unknown to the candidate, submitted in duplicate on different days, and identified by different sample numbers) of 
(1) standard reference materials, (2) working calibration and test materials (WCTMs), (3) nondestructive assay reference materials, or (4) mass reference materials, as appropriate. In the test procedure referenced, ${ }^{(2)}$ nine test samples covering three different concentration levels were submitted to each candidate. The measurement standard deviation and bias estimates from the candidate's results were evaluated to determine if they met preestablished qualification criteria.

Similariy, a qualifying test for performing volume and in-plant density measurements by the candidate can be based on a series of duplicate measurements of volume and density. These measurements should be made at different times and at different liquid levels to avoid the possibility of a consistent error. The precision and accuracy of the measurements should meet pre-established performance criteria. The precision would be caiculated from the duplicate measurement results and the accuracy of the density data may be obtained by independent comparative measurements of the solution densities in a laboratory. The candidate's accuracy in the volume measurements should be obtained from a comparison of the results by the candidate with measurements of the same volume by the examiner or an experienced, qualified technician.

Each candidate should demonstrate the ability to perform calibrations correctly for each type of system for which he is to be qualified. The examiner or a qualified technician should test the accuracy of the calibrations performed by the candidate.

The qualification test for sampling can be based on demonstrated performance of the sampling procedure by the candidate. The examiner should watch the candidate performing the entire sampling operation, including mixing, sample selection, packaging and labeling, and should evaluate the candidate's performance. 


\subsection{REQUALIFICATION}

Either periodic retesting programs or continuous monitoring methods should be used to detect any deterioration of employee performance. If properly structured, an on-going measurement control program should generate data that can be analyzed and used for scheduling the requalification of employees. For example, quantitative measures of performance with respect to accuracy and precision can be obtained through the use of disguised samples of reference materials (e.g., submit duplicate samples on different days with completely different sampie numbers) and replicate samples of process materials. These measures can be an effective test of an employee's continued quality performance and can serve to indicate the need for retraining or requalification. In the case of sampling, periodic checks of the individual's adherence to written procedures provides a source of information that may indicate the need for retraining or confirm the proficiency needed for requalification.

Individuals should be requalified periodically on the basis of performance monitoring data or introduction of a new qualification test. Requalification may also be required for an individual who has been absent from a job for an extended period. New employees who were previously qualified by a former employer should be requalified since qualification is not considered to be transferable between employers. When a change is made in a measurement procedure that is considered significant by the measurement control program manager, a 11 personnel should be retrained and requalified.

\subsection{CERTIFICATION}

Records of the training and qualification for each measurement technician should be established and retained. The records provide evidence of the technician's capability to perform specific measurement functions and certify that he is authorized to perform them. The records can be periodically audited to verify that SNM measurements are being done only by qualified people. 


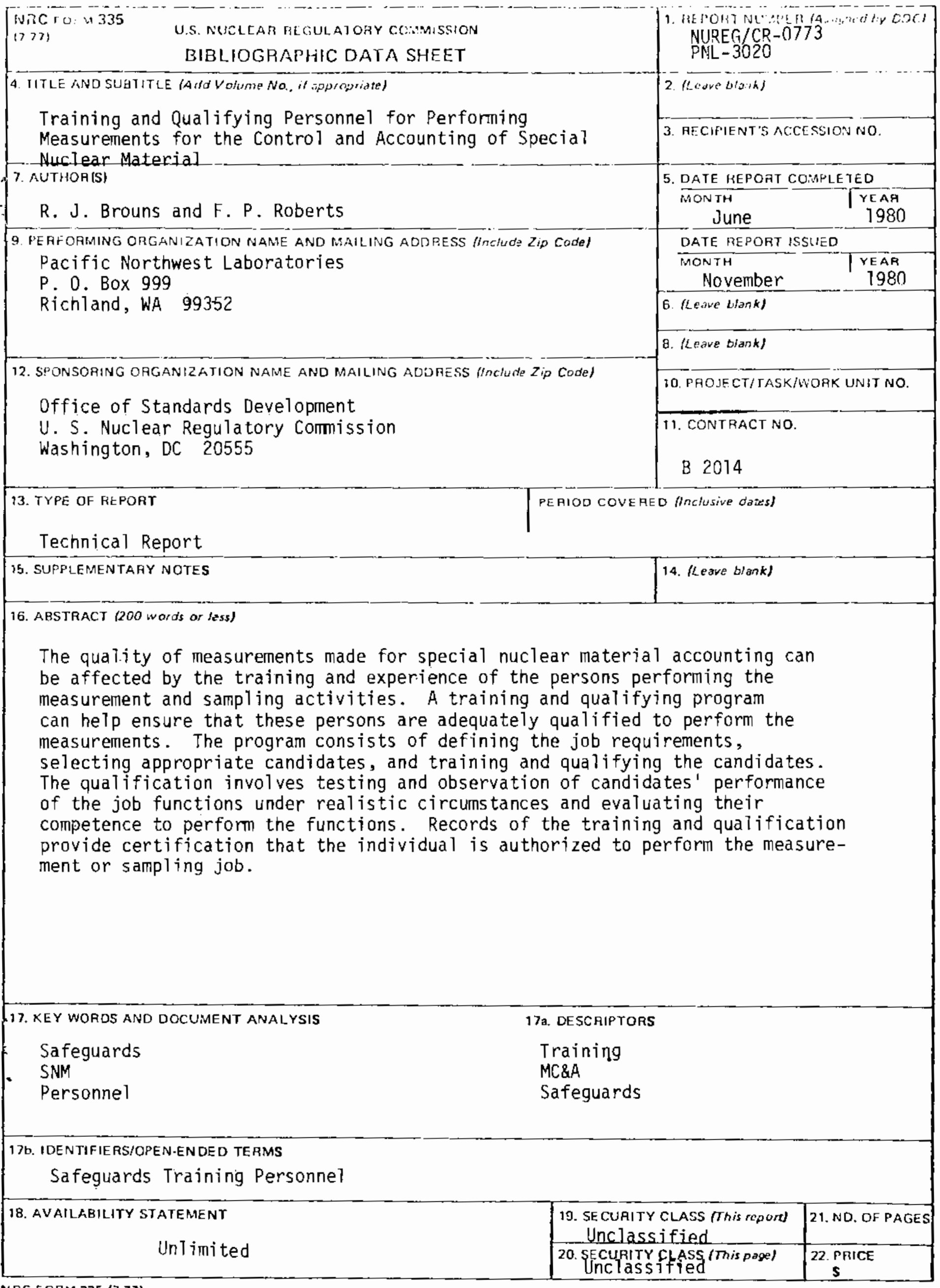


: 